\section{Los caminos de la innovación en Argentina}

Laureano Mon*

Resumen: A través del análisis de la producción de diseño de las regiones del norte de Argen-
tina, se vislumbrarán los caminos de la innovación a la vez que sus formas de comunicación
en los mercados. Los lenguajes creativos son explorados enfatizando los diálogos entablados
por diseñadores contemporáneos con materiales, texturas, formas e imaginarios regionales.

Palabras claves: comunicación - consumidores - cultura - diseño - identidad - producción.

[Resúmenes en inglés y portugués en la página 79]

${ }^{(*)}$ Licenciado en Ciencia Política por la Facultad de Ciencias Sociales de la Universidad de Buenos Aires, y Posgrado Internacional en Gestión y Política en Cultura y Comunicación, en la Facultad Latinoamericana de Ciencias Sociales (FLACSO). [Ver CV completo en página 206]

En un escenario global atravesado por una gran oferta de bienes y servicios innovadores la pregunta que actualmente surge es cómo un diseñador logra diferenciarse frente a otros competidores. Qué debe poseer un producto para ser atractivo y ganar mercados. Ya no basta sólo con desarrollar indumentaria, joyería, objeto u mobiliario inéditos para esas disciplinas, sino que el universo simbólico demanda protagonismo. Es así como la funcionalidad y prestación de las piezas entablan diálogos con la expresión de un modo de ser y estar en el mundo. Pero ¿de qué modo lo intangible se integra en los productos? Y mejor aún ¿cómo unir lo emocional a lo racional de modo equilibrado? Esa incógnita podría complejizarse si agregáramos la necesidad de hallar estrategias de bajo costo para alcanzar un mejor grado de posicionamiento en los mercados internacionales. Asimismo, el requerimiento de dialogar con públicos diversos y lejanos nos desafía a pensar lenguajes universales sin perder singularidad.

El consumidor está esperando productos que no hayan sido visto antes, por ende, para poder exportar los diseñadores deben pensar primero cuál es el producto que tienen, sabiendo que un diseño debe ser innovador y genuino, dos adjetivos que hay que pensar para cualquier cliente en el mundo (Trosman, 2012). 
Y en este sentido, este artículo se centra en esos dos valores, 'innovador y genuino', desde una mirada del diseño producido en dos regiones de Argentina: el noroeste -que abarca las provincias de Salta, Jujuy, Tucumán, Santiago del Estero y Catamarca- y el noreste -comprendida por Misiones, Corrientes, Chaco y Formosa-. A lo largo de un recorrido caprichoso y parcial, observaremos algunas operatorias y resultados que emergen de estos territorios con el objetivo de dilucidar qué podría ser atractivo de comunicar para llegar a públicos más amplios.

La producción de diseño en Argentina ha tomado un ímpetu significativo en los últimos diez años. De manera innata, cientos de diseñadores han comenzando a desarrollar piezas contemporáneas con grandes dosis de originalidad, en un ejercicio creativo que reinterpreta tanto su contexto productivo como cultural. Los límites se cruzan en una urgencia por imaginar trayectos inéditos. En ese camino, la innovación en torno a aspectos constructivos, estéticos y funcionales de los productos, entabla diálogos fructíferos con los horizontes geográficos y simbólicos del entorno. Y un modo de hacer las cosas emerge naturalmente de fusionar los saberes ancestrales con los procesos industriales. Las piezas de diseño adquieren, entonces, una trazabilidad compleja que integra en su concepción aspectos racionales y emocionales.

El norte del país es un territorio de fructíferas innovaciones potenciadas por escenarios que poseen una naturaleza rica en recursos unida a una cultura diversa que contiene las influencias de todos los pueblos que confluyeron en su integración -originarios, europeos y de América Latina-. Esto último se traduce en la disponibilidad de un amplio acervo de saberes, técnicas y oficios heredados, posibles de vincularse con las últimas tecnologías que provee la industria. Es importante tener en cuenta que la mayoría de las micro y pequeñas empresas de diseño, y aquí haré referencia al segmento 'de autor' sobre el cual nos centraremos, hacen un uso intensivo de la mano de obra -principalmente la creatividadmás que de capital -no hay grandes inversiones en maquinarias. Relacionado con esto último, la producción de esos emprendimientos está orientada a bajas escalas de bienes, siendo un elemento estratégico las series limitadas de productos. En muchos de esos casos, la unidad productiva no está pensada como una unidad de negocios más amplia que pueda brindar servicios, aunque deberíamos establecer excepciones para el diseño industrial, más propenso -por su antigüedad y evolución en el país- a ese tipo de acciones.

Es por ello que una de las características más destacadas del diseño del norte es la fusión constante entre procesos industriales y artesanales. Dicha operatoria que involucra materiales y procesos con lógicas diversas -y por momentos antagónicas- convergen en soluciones proyectuales y productivas aplicadas a todo tipo de productos: tanto indumentaria, joyería y calzado, como objetos y mobiliarios. La fluidez desarrollada para agregar rasgos diferenciadores en las piezas de diseño tiene directa relación con los recursos y tecnologías disponibles. Esa operatoria y modo de hacer es lo que va constituyendo una identidad propia, imprimiéndole a los objetos una vibración particular plausible de diferenciarse de otras producciones.

En Curuzú Cuatiá, sur de Corrientes, la diseñadora Lucía Beláustegui define aspectos morfológicos de su colección Enramada-significado de la palabra 'chamamé'-, a partir de dibujos proyectados por la sombra de la superposición de las ramas de los árboles en el suelo, a los que somete a una síntesis para convertirlos en la matriz de piezas elaboradas 
en suela lijada. La combinación de materias primas producidas en el sur de la provincia, como la mecha de lana paralelizada -sin hilar- se logra por medio de la técnica de tejidos a dos agujas o crochet, sumando a ello textiles sintéticos e industriales, como el jersey y la gasa, para generar colecciones de prendas urbanas. Atravesando el territorio de este a oeste, podemos sumergirnos en la familia de productos de la firma Santos Liendro donde el oficio tradicional de la orfebrería se combina en indumentaria -aplicando teselas de alpaca sobre tejidos de punto industriales, como el modal-, en el calzado -con plataformas y cerramientos de metal cincelado, combinado con barracanes y pieles-, en luminarias -donde chapa reciclada de contenedores de alimentos sirven para armar los soportes combinados con cuero de cabra para las pantallas-o en mobiliarios - mixturando maderas de la región con tejido típicos de la zona industrializados, como el aguayo-.

Ese modo de construir con los recursos materiales, humanos y tecnológicos disponibles, es constitutivo de los lenguajes de diseño impregnando todo el proceso proyectual y productivo de un espíritu particular. La experimentación constante en base a esos recursos se traduce, por ejemplo, en la Lámpara Lumino de Renzo Strada Estudio Emergente, construida en listones de palo amarillo que desarrollan una forma prismática produciendo un quiebre en uno de sus extremos, con un perímetro interior con marco de aluminio para sujetar el acrílico grabado con dibujo de lamparitas iluminadas con sistema LEDS.

Un rasgo que nos permite intuir una identidad es la habilidad que poseen los diseñadores para trabajar los materiales propios de la región incorporando, por ejemplo en el noroeste, fibras naturales de ovinos y camélidos, metales como la alpaca y cobre, maderas de cedro, cardón y palo borracho; y cuero vacuno. Los elementos autóctonos funcionan como anclaje para referenciar territorialmente la producción de los creativos a la vez que su particular manera de hacer, impregnada por la picardía de la cultura local, introduce elementos desconcertantes que traen un relato elocuente y contemporáneo. Así podemos hallar la colección de metal de Juárez de la Cámara en la que sus objetos tienden a desafiar la percepción del espectador, donde una vasija de gran tamaño trabajada en alpaca oscurecida con técnicas de envejecimiento prematuro nos remite al encanto de una vasija de barro. También es de su autoría el conjunto de piezas en alpaca pulida con burbujas moldeadas sobre la superficie, en un guiño a la ciencia ficción. Ambos trabajos son perfectos exponentes del juego vertiginoso de texturas que los hacedores hacen fusionando el saber del diseño con el de los oficios tradicionales, como la orfebrería. Del mismo modo, Renzo Strada Estudio Emergente propone Quirquincho, una banqueta de forma orgánica -similar al animal al que hace referencia su nombre- desarrollada en arandelas de descartes, revestimiento interior de piel sintética, estructura interior de caño, patas de acero tubular en forma cónica y terminación con baño de platil.

Interesante es ver que esa utilización de materiales como el metal, y su capacidad de transformación, escapan a los rubros donde habitualmente solemos verlos como en el mobiliario y la joyería. Tal es el caso de la cartera Quri de Oliva hecha de alpaca en una estructura rígida y geométrica con incrustaciones de bronce y fuelle de malla de trébol labrada enteramente a mano. Del mismo modo Puro Postigo propone collares de base geométrica de cuero vacuno con apliques de alpaca y apliques sobre cuero de cabra pintadas con tinta. En esa habilidad innata para cruzar los límites podríamos hallar un modo de concebir la disciplina. 
En torno al uso de fibras animales Maloca desarrolla el chaleco Alpacuno realizado con picote de fibra de llama, en dos piezas únicas en delantera y espalda, compuesta por un pachtwork de retazos y uniones en crochet. Objetos de Agrado propone collares de fieltro con tachas metálicas así como lámparas tejidas, mientras que Ansiosa Hormona explora la posibilidad de un contenedor de lana tejido manualmente configurando formas orgánicas y asimétricas. Por último, la firma jujeña Puisca desarrolla petos de alpaca texturada combinada con lana pura de oveja teñida con tintes naturales.

En el noreste del país, donde abunda el sol y el agua, la fibra de algodón toma protagonismo como especie vegetal autóctona, material que ha acompañado la historia productiva de las comunidades desde tiempos remotos. Actualmente, el hilado y tejido de algodón se realiza de manera industrial en grandes cantidades para la fabricación de todo tipo de telas, utilizadas por los diseñadores de indumentaria: tejidos jersey, rib, pique y friza, en tejido de punto; gabardina, denim, percal, loneta, lienzo, camisería, voile y sarga, en tejido plano. La cualidad de resistencia, gran absorción y facilidad para el hilado, convirtieron al algodón en una de las fibras más importantes de la industria textil. La tucumana Josefina Luna desarrolla vestidos compuestos por algodones de tres tramas diferentes combinados con cordones de algodón en distintos tonos y teñidos artesanalmente. Las firmas jujeñas La Primitiva y Koka Andina, conciben prendas a partir del pachtwork de barracanes y tejidos planos industriales, como friza y denim, pintados sobre la superficie por artistas de Tilcara y avíos de cerámica en arcilla. También en las superficies de las piezas de éstas tres firmas, emergen simbologías de la cultura andina a partir de un ejercicio de observación y extracción de patrones gráficos de signos ancestrales para estampar sobre los textiles. Por su parte, la diseñadora chaqueña María Emilia Velasco tomó el misticismo de la fibra de algodón y la tradición de su cultura productiva, para generar colecciones que exploran las posibilidades del material en paños industriales y tejidos artesanales, logrando prendas que juegan con texturas que combinan serigrafía, calado, trenzado y bordado. Para la colección Samuhú, término guaraní que significa 'palo borracho', María Emilia "se inspiró en el fruto del árbol y transfirió a las piezas las reminiscencias del algodón con sus semillas, estampando la flor de la especie sobre los tejidos puros, en una paleta de color donde prevalecen los tonos rosados" (Rodríguez, Mon, Zander, et al. 2012). Esa misma especie eligió la salteña Rita Fiad para tributar con Espíritu del Palo borracho, un conjunto de jarrones de cerámica esmaltada en color negro con una morfología orgánica con protuberancias que simulan las espinas del árbol al cual rinde tributo, complemento de vajillas de cerámica esmaltada con terminaciones en fibra vegetal tejida. También la ceramista misionera Lujan Oliveira parte de los recursos de esa disciplina del fuego para elaborar joyería contemporánea combinada con tejidos industriales con reminiscencias simbólicas de la región a orillas del Paraná.

La posibilidad de incorporar materialidades diversas en una misma pieza, trabajadas con técnicas que fusionan armónicamente procesos industriales y artesanales, es una constante del diseño del norte, siendo uno de sus rasgos más innovadores. Pachacuti, la colección de zapatos de la firma salteña Mafe, seduce por sus prodigiosas terminaciones, su inevitable respeto para con el modo tradicional de confeccionar el calzado y sus delicados juegos de materiales; combinando barracán, descarne gamuzado, cuero flor, en sus interiores badana de oveja y suela de cuero; por ultimo una serigrafía sella su estilo juvenil con un 
dibujo simplificado de una llama, el animal insignia de su zona.

La madera es otra de las materialidades presentes en el norte disponibles para ser utilizadas por los diseñadores. En el caso del noreste el algarrobo, quebracho colorado, quebracho blanco, lapacho, urunday, timbó blanco, guaraniná y palo blanco, son algunas de las especies con implicancias constructivas, funcionales y estéticas particulares. En este sentido, la diseñadora industrial Alejandra Rumich desarrolla piezas que dialogan con su entorno natural y productivo. La línea Irupé incluye mobiliario realizado con madera de ibirá pitá -palo lanza ó guayaibí-, tejido artesanal de carandilo -cestería- y cristal. En algunos productos explora la combinación del algarrobo - de uso tradicional- con diferentes tipos de cueros aplicados en morfologías innovadoras. Hacia el noroeste, en Purmarmarca, Jujuy, El Chulita genera mobiliario en madera envejecida combinados con laja esculpida, caña silvestre, hueso de caballo, asta, tiento, cuero crudo, lonja sobada, tejidos autóctonos y apliques de cerámica con figuras de los antepasados de la región. En Salta, Gonzalo Verasaluse desarrolla luminarias de estructura de madera de la región recubierta de adobe con luces dicroicas. Por su parte, Alfonso Vallejos, a través de su firma Conserva, trabaja la fusión de metales a reciclar, combinados con materiales naturales como madera, bambú, lana y alpaca, para crear piezas decorativas con una gran simbología, como cuando incorpora dibujos Wichís a través de la pintura o de tejidos que aplican a la superficie de los objetos.

La rica trazabilidad de las piezas de los diseñadores del norte enlaza referencias a la naturaleza y a la simbología de la región, pero esa marcada territorialidad incorpora en su relato elementos contemporáneos que permiten establecer diálogos con consumidores de diferentes latitudes. Esos relatos nos invitan a pensar acerca de las interacciones que se generan entre las diferentes tecnologías que tienen disponibles los diseñadores a partir de las cuales producen cruces y reinterpretaciones generando valor agregado en los bienes. En este sentido, Lorena Sosa, para quien es habitual combinar las técnicas tradicionales de la confección y la orfebrería, ahora desarrolla una cartera construida por dos círculos de acrílico transparente calados con láser, con fuelle interior de textil traslúcido alforzado que hace de nexo entre ambos frentes; esa pieza es el complemento de un vestido compuesto de capas asimétricas, cintas de colores que generan recorridos visuales, bordados y piezas de acrílico caladas en láser con detalles en breteles.

Las tendencias actuales del mercado hacen hincapié en la necesidad de crear fuertes identidades de marca a partir de las cuales trazar estrategias integrales de comunicación. Para ello es necesario que un relato singular sea capaz de seducir al consumidor introduciéndolo en una experiencia que supere el producto en sí. En el caso del diseño de autor la configuración de esa historia debe considerar la rica trazabilidad que poseen las piezas como un elemento que claramente puede diferenciarlas de aquellas generadas por la industria masiva. Ahondando en aquellos lazos que se establecen a través del concepto de innovación, aspectos estéticos y características constructivas, la dimensión simbólica puede ser un elemento a potenciar en los discursos y promesas de las marcas regionales. Esas historias genuinas deben expresarse a través de múltiples canales sin perder de vista que los bienes con valor agregado tienen la ventaja de poder hablar por sí mismos, generando un vínculo diferente con los consumidores. 
Las marcas que son potentes son aquellas que construyen un relato singular. El cómo se va a comunicar es la pregunta. La respuesta en con relatos únicos, sensibles, potentes, próximos, que conecten con el consumidor. Ese relato debe surgir de una realidad, ser un discurso sincero. (Batemarco, 2012)

En éste punto, el diseñador debe poder observar el universo local que lo rodea para poder extraer de él aquellos elementos y signos que sean coherentes con su trabajo para poder potenciar la comunicación. Reconocer las inspiraciones que subyacen al proceso creativo y productivo es fundamental. Esto es, no es lo mismo comunicar la joyería contemporánea producida por Humito -Yazmin Zampaca- realizada en base a una virtuosa combinación de materiales y colores de la naturaleza sin destacar que su propuesta se nutre de la selva misionera a la vez que el uso de las semillas remite al valor que le asignaban los pueblos originarios de la zona a éste tipo de piezas suntuarias. La elección del modo de comunicar a través de la campaña gráfica, el diseño de marca y la experiencia de compra, debe ser coherente a ello potenciando ese relato genuino. También es fundamental identificar adecuadamente el público que ello puede tener, quienes le otorgarán el verdadero valor a los productos junto con su historia.

El juego con las diferentes posibilidades que brindan actualmente las herramientas de comunicación para las empresas de diseño de indumentaria de autor depende enteramente de la habilidad del creador y su equipo de profesionales, quienes pueden optar por uno o varios canales de acuerdo a la pertinencia de lo que se desea comunicar como así también los costos que se pueden afrontar. Sin lugar a dudas una firma que se posicione dentro del segmento de diseño de vanguardia deberá buscar un mensaje y una estrategia comunicacional diferencial frente al resto de los competidores que sea coherente con la imagen de originalidad que brinda. Para ello imprescindible poder identificar el valor agregado que tiene el producto así como el sello de diseño del autor que es necesario comunicar. (Marino, Marré, Mon, 2012, p. 53)

Los primeros motivos de la elección de un consumidor son mayormente irracionales, luego lo racional interviene para justificar esa elección. Es por ello que es necesario ahondar en "estrategias cualitativas que permitan al público conocer de modo más agradable y completo el producto y la identidad de la marca". (Marino, Marré, Mon, 2012, p. 53)

Las experiencias sensoriales se plantean como uno de los caminos imprescindibles para generar mensajes profundos y diferenciados. Por ejemplo, ingresar a una tienda donde se venden los productos de Humito y poder percibir estímulos olfativos vinculados a la selva misionera, sería un buen punto. Del mismo modo, una campaña gráfica con una mirada contemporánea que ponga en valor el misticismo de la joyería y sus lazos con tradiciones ancestrales, puede ser un buen camino. En éste punto, Yazmín Zampaca junto con el fotógrafo Humberto Acosta, desarrollaron un trabajo fotográfico denominado La Segunda Piel donde una joven mujer de rasgos fuertes emergía de las místicas aguas del río Paraná usando las piezas como indumento de un ritual. La potencia de esa imagen seduce a pú- 
blicos amplios que buscan diseños imbuidos de una trazabilidad sensible que se incorpore orgánicamente a sus discursos personales.

Las regiones que poseen culturas diversas y ricas en elementos simbólicos son fuentes inagotables de relatos para los diseñadores, quienes reactualizan esos imaginarios a través de un lenguaje contemporáneo. Los productos innovadores se impregnan entonces de historias genuinas que sólo hace falta comunicar de manera adecuada. El diseñador Agustín Bossini Pithod desarrolló una colección de prendas urbanas masculinas denominada Siesta Santiagueña en la cual tomó esa costumbre presente en pueblos del interior del país reinterpretándola en recursos de diseño.

En la siesta santiagueña el primer contacto con el afuera es con un todo blanco cegador, que confunde, encandila los sentidos, nuestros ojos, en el afán de volver a lo real, nos regalan manchones acuarelados de colores vibrantes, mezclados, relata el diseñador, quien asocia el silencio de esa hora con siluetas clásicas, varoniles y holgadas de voz baja, en rezo piadoso y constante en un ejercicio que vincula, a la vez, la indumentaria con la poesía (Bossini Pithod, 2012).

Del mismo modo, los productos de la firma Contexto Textil, integrada por la escritora Cecilia García y la diseñadora gráfica Luján Signoris, son expresiones del entorno material, social y cultural chaqueño. Su primera línea de estampas también remitió a la Siesta con atención en dibujos de la fauna y flora de la zona, generando estampas aplicables a objetos de decoración para el hogar como así también en prendas simples.

Consciente de ese entorno que brinda no sólo recursos materiales y humanos, sino también inspiracionales, la diseñadora Mirta Pérez elabora sus prendas a partir de la combinación de diferentes técnicas de telar, como las de telar María, Guaraní y cuatro cuadros. En sus complejas piezas suma apliques, terminaciones y detalles en tejido crochet, dos agujas, bordados, ñandúti y encaje jú, típicos de Misiones, provincia en la que produce. En esa misma línea de trabajo la diseñadora de indumentaria Kalu Gryb explora la belleza imperfecta del monte chaqueño, atravesado por esas grietas que el sol implacable deja en la tierra y en la piel de los que la trabajan. Su colección Harapos de una tierra sin savia incorporó materiales rústicos, crudos y naturales, como cuero y paños de algodón, revalorizando una estética modesta, humilde, indiferente a la ostentación, propia de la cultura rural. Cuando nos enfrentamos a productos que, más allá de sus innovaciones, son relatos en sí mismos, la atención debe estar puesta en cómo transmitir esa trazabilidad desde códigos comunicacionales actuales atravesados por la inmediatez y sobresaturación. Hallar una lógica que permita transmitir de manera genuina y útil esas diferencias que las marcas y los bienes poseen, sin lugar a dudas implica desarrollar paradigmas locales que incorporen esa vibración de la identidad pero que proyecte un mensaje universal capaz de establecer diálogos con consumidores de todo el mundo interesados en esos desarrollos.

Manuela Rasjido, nacida en el norte de la provincia de Catamarca, en la antigua Santa María, concibe sus prendas inmersa en ese espíritu místico que poseen los Valles Calchaquíes, sitio que describe modestamente como un 
lugar rodeado de montañas de colores y atardeceres con luces cambiantes. (Saulquin, 2010, p.3)

Esas percepciones del espacio se reflejan en su trabajo a través del tratamiento del color donde abundan las tonalidades terrosas, las texturas ásperas y las formas geométricas, en piezas construidas en tejido de barracán. En la colección El vuelo de las raíces propicia de manera más amplia una lectura universal de esas influencias locales, trazos que la indumentaria comunica como mensajera de una honda sensibilidad. (Rodríguez, Mon, Zander, et al. 2012)

Frente a un fructífero y diverso panorama de producción de diseño es fundamental, entonces, crear marcas con fuertes identidades que permitan una conexión profunda con el consumidor ávido de relatos y experiencias de consumo únicas. Para ello, reconocer y comunicar el universo proyectual, productivo y simbólico en el que está imbuido el diseñador es un rasgo importante de autenticidad que convierte su historia en genuina. $Y$ en esa línea, expresar claramente los valores de las empresas de diseño es una estrategia inteligente de posicionamiento que complementa los rasgos intangibles, ya que le brindamos información confiable al consumidor para que pueda también decidir conscientemente la elección del producto.

\section{Referencias Bibliográficas}

Batemarco, F. (2012). Citado en: Marino, P., Marré, S., Mon, L. (2012). Diseño de Indumentaria de Autor en Argentina 2012. Diagnóstico productivo e impacto económico basado en la Encuesta Nacional de Diseño de Indumentaria de Autor 2012, Buenos Aires: INTI - Fundación Pro Tejer.

Bossini Pithod, A.(2012). Citado en: Rodríguez, S., Mon, L., Zander, K., et al. (2012) INTI Mapa de Diseño, 101 diseñadores de autor. APP, cap. Territorio de Contrastes. Buenos Aires: Observatorio de Tendencias INTI.

Marino, P., Marré, S., Mon, L. (2012). Diseño de Indumentaria de Autor en Argentina 2012. Diagnóstico productivo e impacto económico basado en la Encuesta Nacional de Diseño de Indumentaria de Autor 2012, Buenos Aires: INTI - Fundación Pro Tejer

Rodríguez, S., Mon, L., Zander, K., et al. (2012) INTI Mapa de Diseño, 101 diseñadores de autor. APP, cap. Territorio de Contrastes. Buenos Aires: Observatorio de Tendencias INTI. Saulquin, S. (2010) Catálogo El Vuelo de las Raíces. Buenos Aires, Manuela Rasjido.

Trosman, J. (2012). Citado en: Marino, P., Marré, S., Mon, L. (2012). Diseño de Indumentaria de Autor en Argentina 2012. Diagnóstico productivo e impacto económico basado en la Encuesta Nacional de Diseño de Indumentaria de Autor 2012, Buenos Aires: INTI - Fundación Pro Tejer. 
Summary: Through the analysis of the production design of the northern regions of Argentina, the author envision the ways of innovation while their communication in the markets. The creative languages are explored emphasizing the dialogue initiated by contemporary designers with materials, textures, shapes and regional imaginary.

Keywords: communication - consumers - culture - design - identity - production.

Resumo: Através da análise da produção de design das regiões no norte de Argentina, se distinguirão os caminhos da inovação as vezes que suas formas de comunicação nos mercados. As linguagens criativas são exploradas enfatizando os diálogos iniciados por designers contemporâneos com materiais, texturas, formas e imaginários regionais.

Palavras chave: identidade - design - cultura - produção - comunicação - consumidores. 